\title{
PERCEIVING THE CONTENT OF TELEVISION PROGRAMS FOR CHILDREN AND ADOLESCENTS
}

\section{Husejn Musić ${ }^{1}$ \\ Mujo Kućanović}

Faculty of education, University „Džemal Bijedić, Mostar

Mixed Secondary School ,Musa Ćazim Ćatić" Olovo

Received: 01.10.2013.

UDC: $37: 654.197-053.5 / .6$

Professional paper

Accepted: 28.11.2013.

\begin{abstract}
The previous research, daily occurrences and an information perceived through the mass media indicate the complexity and topicality of problems considered in this paper, as well as the need of its' examination from several aspects, with the aim of identifying, preventing and overcoming the very frequent displays of unacceptable behavioural patterns in children and adolescents in their environment. More precisely stated, the television with its program content, information and messages, in addition to the family, educational institutions, and other factors has a large and responsible part, influencing both positively and negatively the quality of an entire educational process and development of children and adolescents.
\end{abstract}

Key words: child, adolescent, upbringing, television, contents of television program, family, audience.

\section{INTRODUCTION}

In the psycho-physical development of a man, childhood represents one of the most important periods and it covers almost one fourth of the human life, with traces clearly tangible during the entire development, directly affecting he formation of human thought and behavior. Childhood in this sense begins at birth and lasts until adulthood. Our research puts emphasis on the content perception of the television programs in children and adolescents; however, we define two specific periods, namely: medium (from 6 to 11 years) and late childhood - adolescence (from 12 to 18 years). A child growing up during has a wide range of needs and activities necessary for emotional, intellectual and physical balance, and one of the most relevant needs is the need for knowledge by means of curiosity which further increases and elevates the aforementioned need. The nurturing process starts very early from the moment when the child begins to speak and think, more specifically, when a child establishes the communication process with the environment, acquires additional knowledge, which results in the development of abilities, skills, habits, attitudes, and overall ideas about what surrounds it. Adults should focus their attention to the stimuli, information given to the children and the consequences it might have in its development stages (Musić, 2011). Educational value of television depends on the way in which it is used, perceived, who selects and what kind of program selection is done, which is one of the essential questions.

\section{${ }^{1}$ Correspodence to:}

Husejn Musić, Faculty of education Mostar

USRC „Mithad Hujdur Hujka”, 88104 Mostar, Bosna i Hercegovina

web http://www.nf.unmo.ba/

Phone: +387 61 413-34 
Educational value of television ${ }^{2}$ depends on the way in which it is used, perceived, who selects and what kind of program selection is done, which is one of the essential questions. Television as the means of mass communication for educational and nurturing purposes (television in school and in teaching, Schule und Fernsehen in Unterricht) can be employed via Broadcasting Television Network (open type television) and closed type television with the latest video - cassette methods mostly used schools, families at home, and other educational institutions. Open type television was first used in 1947 in the United States of America (USA) for educational purposes. In the case of former Yugoslavia, Radio Television Zagreb was the first to begin broadcasting the national program in 1956. Radio Television Belgrade followed in 1958 and shortly after the same year Radio Television Ljubljana began broadcasting. The first usage of closed type television was for teaching purposes in 1956 when the cable network was connected to 43 schools in the state of Maryland (USA). The use of television in teaching and extracurricular activities in the former Yugoslavia began 1963 when Television Zagreb started broadcasting programs intended for students and schools to implement educational content. Television can offer a number of exceptional educational programs and documentaries, television dramas, movies, travelogues and other interesting stories. However, the information technology and mass media despite the positive sides unfortunately brought numerous negative effects and problems.

\section{PERCEIVING THE CONTENT OF TELEVI- SION PROGRAMS CHILDREN AND ADOLES- CENTS}

Results of studies examining the perceptions of the television programs content generally indicate the tendency of children to imitate aggressive behavior perceived in the content broadcasted via television programs. More specifically, it was observed that there the scenes of aggression in television programs were correlated with the expression of unacceptable types of behavior (bad actions performed by a "bad guy").

\footnotetext{
${ }^{2}$ Televisionis a telecommunication systemforbroadcasting and receivingmoving pictures and soundsfromgreat distances. The wordtelevisioncomes fromthe Greek wordstele - far and visionwatching. Thisconcept applies toall aspects oftelevision programmingand transmission.
}

Incomplete understanding of the program content often leads children to acquire attitudes, different ways of behavior contrary to the intention of their authors. Generally speaking, the increase in aggressive behavior with children and adolescents can largely be explained as an imitation of violence, behavior of the main characters roles, as perceived in the content broadcasted on television. This view is quite limited and one-sided, but it is still present in public. There is plenty of data to suggest that violence perceived by the content of television programs has much more subtle and dangerous influence on the audiences $^{3}$, such as children, adolescents, and adults. It can be argued that it leads to apathy, passiveness to violence in everyday life, where the children for example perceive are al life war scene in the news program more or less as they would perceive a war scene in a movie. The significance of such a perception is that a child learns that violence is not dangerous for him/her, and becomes indifferent to violence in everyday life, which makes them more vulnerable as victims to violence around them, and such indifference opens the door to new violence. The negative effects of violence on television are: children become more tolerant of violence and it does not bother them, they develop wrong attitudes towards violence, accompanied with the loss of sympathy for those who suffer from violence, begin to see the world around them as a violent place, having fear they would be in a position to suffer violence, exhibiting antisocial and violent behavior, they are more exposed to violence and are in need of more violence in their games, conflict resolution with violence is acceptable and desirable, they live in a virtual world, not developing their emotional intelligence or self-confidence, they lack creativity while developing depression and insecurity, the wrong perception of violence, violence continuously affects the daily habits and lifestyle.

The fact is that violence actually appears in television programs much more than it appears in the real day to day life. Attempt to protect children from media violence and other inappropriate contents are regulated by Article 17 Convention on the Rights of the Child. This article established a system of tags that should help in avoiding the harmful effects of television contents. Adults should watch television with their children, discussing the content of what was watched on television, can help children better understand the content being viewed while enabling parents to spend more time with their children.

\footnotetext{
${ }^{3}$ The audience is a group of people (although it can also represent a man), which takes part as an active observer of the artistic act-theater performances, movies, concerts, etc.
} 
THE ROLE OF THE FAMILY IN THE CORRECT PERCEPTION OF THE TELEVISION PROGRAM CONTENT IN CHILDREN AND ADOLESCENTS

Mass media communication entered our lives overnight, transformed a good part a modern man and his life while enslaving the young and old. Adolescents and adults sit for hours in front of the television, watching serial soap operas and long " daily news " while children run home out of the yards, schools, interrupting a game when a specific cartoon or some other movie that is filled with violence, aggression, substance abuse, etc. is scheduled to be broadcasted. The most powerful means of mass communication which affect the children and youth is television with program content, which threatens to completely take all the free time including sleep. If we add poorly organized local television stations with low quality shows, cheap info-commercials, movie marathons, various reality shows, our expectations for the future are very bleak and discouraging. When parents neglect the education and nurturing aspect of their children, to point their children in the right direction, children become a problem, a source of annoyance and distress not only for their parents, but also for their community and society as a whole. Many parents are not aware of the responsibility they have towards their children, some of them completely ignored their responsibilities leaving their children to find their nurturing and education on the streets, television and the Internet, while putting the accent and focusing their activities towards acquiring more money and material goods. Parents must be involved in the control of the television programs that are being watches, avoiding low quality shows and focusing on building a television culture based on educational programs both for them and their children. This culture must first be acquired by the parents and then transferred to their children. This is certainly not an easy task but it is worth trying or at least attempt to change something. The family should be impose and respect a time restriction for watching television programs such as: for children in elementary school an hour and a half a day (on average), for children in pre-school ages an hour a day and for children in high school two hours a day. Saturdays and Sundays are days when an extension of two to three hours should be allowed with the inclusion of Internet usage. Any family that he succeeds in these time limitations, solves two major problems:

Convinced their child to use time according to their interests and schoolwork while independently selecting quality television programs,
The child will have plenty of time for a number of other social activities, leisure and other types of events (playing in the yard, tours, sports and other activities), which will help the child to return to a natural and normal course of life and work as it progressed over thousands of years, and produce healthy and happy future generations.

Families who for various reasons are not able to limit the time watching television programs do a disservice to their children. (Mihajlović, 2004, p.13). We are free to say that such children act as an alcoholic for which one or two glasses of alcohol are sufficient to be drunk, they do not know and cannot draw the line or stop watching television, which then becomes an opiate with no limits. Another very important issue is the educational value of selected television programs. Parents should try to develop the criteria with their children, feeling for the quantity and quality, the ability to perceive only the quality values from the programs that are being watched and so on. This area is in most cases properly addressed and more organized in schools, therefore, parents should help and support such efforts. With preschool and elementary school children parents can talk about the perceived content, which solves the problem of one-way communication and passivity of children in the family. We tend to hinder the children if we allow them on daily basis to perceive various television shows with aggression, video games, which only entertain the children and provide them with no educational values. Children waste their free time, they become intellectually lazy, they do not participate, think, solve, they are passive observers, and many things pass them by and go to waste. Third question and a very important problem is the presence of violence on television, which attracts young people and children to this type of genre and other works which can already be seen in almost every cartoon. Due to the large presence of violence, prostitution, aggressiveness in the television program content, one could be very doubtful of positive and negative characters and roles. If the main character in a feature film to prove his innocence, justify their actions, demonstrate fairness, carry out justice, uses various weapons to kill more than a hundred people, destroying dozens of cars, damaging several buildings, etc., could lead one to conclude that the educational effects of the observed television program are questionable and doubtful. Young people and children often identify themselves with the lead roles and characters that are in the film, which are mostly, strong, quick, agile, courageous, and fierce in overcoming their many enemies emerging victorious ate the end of the film. 
Considering the various negative effects there is a possibility that the process of identifying within this population could isolate a new , Batman, Tarzan, Ninja, Rambo, Superman, Spiderman and so on, which could use concealed weapons, explosives from the last war in the former Yugoslavia and for no reason, kill, injure innocent bystanders, drop a bomb into an open window of a neighbor 's house, blow up a garage, put a bomb in a school, coffee shop or some other place of mass public gathering. A special role on the psycho-physical and mental development of children and adolescents and their parents, have played the soap operas/series, with more than a hundred episodes (Esmeralda, Gaviota, Marisol, Desperate Housewives and others) saturated with love, pornographic content that tend to lead to prostitution, where usually a richprince falls in love with some poor girl, and vice versa, and after many obstacles that are usually accompanied with various insinuations, gossip, telling lies, rape, murder, finally ends happily. These contents of television programs are harmful, especially if you watch them late in the evening, they make it difficult to sleep, could change individuals biorhythm ${ }^{4}$ and systematically destroy the psycho-physical structure of the viewer, excite the imagination, the real objective world is transformed into an imaginary one, precious time for schooling and extracurricular commitments is wasted, etc. Every parent should pay special attention to and put emphasis on this issue. A possible solution for this problem should be found in some kind of appropriate but also attractive replacement activity. Educational, cultural, public institutions, families and all those involved in education, should find away to offer to children and provide them with interesting cultural activities, give them the opportunity to use their energy through the proper channels with adequate activities such as: sports and other competitions, various activities in the nature and enable them to express themselves in other ways.

${ }^{4}$ Biorhythm theory assumes that since birth a man, or more precisely his emotional, physical and intellectual abilities under go favorable, un favorable and critical moments.

\section{THE ROLE OF THE SCHOOL IN THE COR- RECT TELEVISION PROGRAMS CONTENT PERCEPTION IN CHILDREN AND ADOLES- CENTS}

Educational television as an audio-visual communication and a teaching tool stimulates cognitive, emotional and conative personality development of students. The importance of television is reflected in the fact that it presents a student with geographically and temporally distant venues, events, stimulating their activities and encouraging independent study, creativity and freedom of expression. Transmission of information, presentation of content, activities and knowledge through television programs in teaching involves three stages: preparation of teachers and students, monitoring the content of television programs, and the final stage. Preparing students and seminars for teachers includes activities related to the introduction to the topic of the program, the accompanying texts, materials, arrangement of the students, introduction to the content of the shows by repeating the material/topic, encouraging discussion and debate on the content that will be presented. Monitoring the content of television programs usually runs without interruption, but in the era of video - technology, internet, presented content can be divided into several smaller parts - sequence followed by a brief summary and analysis, rewinding and identifying important details and scenes, their acceleration or deceleration, and the rule is that the teacher provides continuous monitoring, information dissemination, listening to students, with little or no suggestion, calling attention to something important, and with older students an addition, where students should be taking notes about some important information and details. In the final stage, it is essential to briefly summarize the presented content and activity, perform analysis, and clarify all misunderstandings and misconceptions. One could say that television programs content in the process of communication, education and leisure activities, moving images, sounds, using other numerous communication teaching materials, very specifically and dynamically informs and presents students with information about objective reality, attracting and developing attention, arouses curiosity and interests, cultivates motivation, providing the appropriate level of knowledge, information, intellectual capability, independence, criticism to the work of students and teachers, facilitates the work of the teachers, gives teachers the ability to engage in more subtle and important issues of educational work while deepening general, educational and cultural literacy. 
The children and adolescents should be able to participate in different of school activities, community organizations, where they will actively participate, be responsible and successful in accomplishing a specific task. Finally, we must emphasize the importance of social factors which must be included in the fight and resistance against organized violence primarily violence on television. Sales and commercialism should not be given priority when choosing the film content. If all else fails, one should resort to legal means of taxation of all television programs with no real social, cultural, artistic and educational values and especially in the form of violence and include all low quality programs.

\section{CONCLUSION}

Many scientists are of the opinion that watching television for a preschool child is physically very strenuous activity, in which all of his muscles are tense, rapid heartbeat is present, his body is passive, all the physical and mental processes are accelerated, which results in stress and anxiety. We should bare in mind that this is a very intense emotional experience and that a preschool child may be submitted to such experiences for only short periods of time. So, in addition to the physical effects we must not ignore the impact of television content on the psychological development of children. Any child at the ages of three or four years is able to observe adults around them and imitate their behavior, movements, and facial expressions. In the same manner it is capable to identify himself with the main characters, imitate their behavior, movement, speech, etc. Therefore, it is extremely important to show children which television programs they can and should watch. The results of many studies indicate that television as a means of mass communication has become an important part of children's lives, which initiates a concern that television (and in a wider context the media) with their inappropriate programming increasingly threaten the educational role of the family, schools, educational institutions and other relevant factors. The length of time children spend watching television, regardless of content should be controlled by their parents, mostly because it reduces the time that can be spent on more useful activities such as reading, playing, recreation and other sports, hobbies, meetings, etc. By choos- ing the content of television programs for children in their early childhood, prerequisites for proper physical and mental development of the child are created, building the proper manner and style in which television as a means of mass communication is used. Children should always be reminded that their energy should be directed towards outside games, sports and other various types of mental and physical recreation because in the long run it will make it easier for them and enable them to normally develop and live. Also, please note that it is imperative that educators act preventively against inappropriate use of television and its programming content while at the same time using its many resources which would enable them to achieve a positive impact on all aspects of childhood psycho-physical and mental development, improving the quality of all segments of educational work and the development of media culture for the children (Music and Muratovic, 2010). Research results show that children and adults spend more hours per day in front of the television, that television is the means of mass communication, and that it is an important educational factor with a positive and negative impact on the overall physical and mental development of an individual. Research has shown that there is a causeeffect relationship between implemented programming content of television shows filled with violence and other negative effects elements with the behavior of children, adolescents and even adults. The parents, educational institutions and broadcasters have to be careful in planning, programming, communication and messaging, content and implementation of activities, as well as their reflections on the overall physical and mental development of a person who perceives experiences and reacts to a message. Television contents have a strong impact on the viewers, respectively, watching television content suggestively acts and leaves a mark on the behavior of individuals more than it is the case with watching a show in a theater.

\section{REFERENCES}

Mihajlović, A. (2004). Internet tehnologija kao podrška obrazovnom procesu. Zbornik radova Jagodina: Učiteljski fakultet u Jagodini i Institut za pedagoška istraživanja u Beogradu.

Musić, H., Muratović, A., (2010). Komunikacija u nastavi. Tuzla: OFF-SET.

Musić, H. (2011). Autoritarna i demokratska komunikacija u nastavi. Tuzla: OFF-SET. 